\title{
TEOR DE FÓSFORO E pH NO BULBO MOLHADO, COM DIFERENTES FREQÜÊNCIAS DE FERTIRRIGAÇÃO, UTILIZANDO ÁCIDO FOSFÓRICO ${ }^{1}$
}

\author{
LETICIA C. FORATTO ${ }^{2}$, JOSÉ R. ZANINI ${ }^{3}$, WILLIAM NATALE ${ }^{4}$
}

\begin{abstract}
RESUMO: A aplicação de fertilizantes fosfatados, tais como superfosfofato simples, superfosfofato triplo e monofosfato de amônio, via gotejamento, pode apresentar incrustações nas canalizações e obstruções de emissores. No presente trabalho, realizado na UNESP/Jaboticabal SP, estudaram-se a distribuição do fósforo e a sua influência sobre o $\mathrm{pH}$ e a umidade em Latossolo Vermelho, fertirrigado durante um mês, com cinco aplicações semanais de ácido fosfórico. Utilizaram-se quatro repetições e oito tratamentos, constituídos da combinação de doses de $\mathrm{P}_{2} \mathrm{O}_{5}(0$ e $50 \mathrm{~kg} \mathrm{ha}^{-1}$ ) e freqüências de aplicação de 1; 3; 5 e 7 dias. Pelos resultados obtidos, observou-se que a frequiência de irrigação ou de fertirrigação não influenciou na distribuição final da umidade no bulbo molhado; aplicando-se o ácido fosfórico, o $\mathrm{pH}$ do solo até $30 \mathrm{~cm}$ do gotejador e até $40 \mathrm{~cm}$ em profundidade foi reduzido, atingindo valor de 3,6, e o teor de fósforo foi maior nessa mesma porção do bulbo, ultrapassando $1.500 \mathrm{mg} \mathrm{dm}^{-3}$. Isso permite indicar que o ácido fosfórico pode ser utilizado em irrigação localizada, com controle do $\mathrm{pH}$ do solo, pois sua redução influencia no desenvolvimento das culturas e, conseqüentemente, na produtividade.
\end{abstract}

PALAVRAS-CHAVE: acidez do solo, gotejamento, incrustação.

\section{PHOSPHOROUS CONTENT AND pH IN THE WET BULB, WITH DIFERENT FREQUENCIES OF FERTIGATION USING PHOSPHORIC ACID}

\begin{abstract}
Phosphated fertilizers, such as superphosphate, triple superphosphate and monoamonium phosphate, applied throught drip irrigation can present pipe incrustations and emitters obstructions. In this research, carried out in the UNESP - São Paulo State University, Jaboticabal - Brazil, it was studied the phosphorous distribution, the influence on $\mathrm{pH}$ and the moisture in one Oxisoil, fertigated during one month, with five applications of phosphoric acid. Four replications and eight treatments were applied, and the treatments combined two rates of $\mathrm{P}_{2} \mathrm{O}_{5}$ $\left(0\right.$ and $\left.50 \mathrm{~kg} \mathrm{ha}^{-1}\right)$ and four frequencies of applications $(1 ; 3 ; 5$ and 7 days). The irrigation or fertigation frequency did not influence the distribution of the moisture in the wet bulb; $\mathrm{pH}$ of the soil until $30 \mathrm{~cm}$ from the drip and until $40 \mathrm{~cm}$ in depth was reduced, reaching value of 3.6 while the phosphorous values were higher in this same region of the bulb, exceeding $1,500 \mathrm{mg} \mathrm{dm}^{-3}$. These results allow indicating that the phosphoric acid can be used in localized irrigation systems, controlling soil $\mathrm{pH}$, because low soil $\mathrm{pH}$ will be able to influence the development of the cultures and, consequently, the productivity.
\end{abstract}

KEYWORDS: soil acidity, drip irrigation, incrustation.

\section{INTRODUÇÃO}

A irrigação está sempre presente na agricultura tecnificada, pois implica maiores produtividades, melhor qualidade do produto e independência do fator precipitação (DALRI \& CRUZ, 2002). NOGUEIRA et al. (2000) relatam que a irrigação por gotejamento oferece melhorias na qualidade dos produtos colhidos, maior rendimento e eficiência no uso da água; além disso, permite a aplicação simultânea de água e fertilizante, possibilitando a utilização mais racional desses, comparada com as formas tradicionais de aplicação. Segundo CHARLESWORTH

\footnotetext{
${ }^{1}$ Extraído do trabalho de graduação do primeiro autor.

${ }^{2}$ Eng ${ }^{\mathrm{a}}$ Agrônoma, graduada pela UNESP - Jaboticabal, lc_foratto@yahoo.com

${ }^{3}$ Eng ${ }^{\mathrm{O}}$ Agrônomo, Prof. Doutor, UNESP - Jaboticabal, Departamento de Engenharia Rural, jrzanini@ fcav.unesp.br

${ }^{4}$ Eng $^{\circ}$ Agrônomo, Prof. Adjunto, UNESP - Jaboticabal, Departamento de Solos e Adubos, natale@ @cav.unesp.br

Recebido pelo Conselho Editorial em: 6-12-2006

Aprovado pelo Conselho Editorial em: 13-7-2007
} 
\& MUIRHEAD (2003), a distribuição da água com irrigação localizada é mais eficiente do que com outros métodos de irrigação, como, por exemplo, irrigação por sulcos.

A utilização adequada dos recursos hídricos garante o aumento da produtividade, entretanto faz-se necessário o fornecimento de nutrientes para as culturas. Nos últimos anos, além da forma tradicional de aplicação de nutrientes, tem sido adotada a fertirrigação, pois permite a aplicação de fertilizantes simultaneamente com a água de irrigação (ELOI et al., 2004).

ZANINI (1991) estudou a distribuição de água em bulbo molhado, com gotejadores de 3 e $6 \mathrm{~L} \mathrm{~h}^{-1}$ e tempos de gotejamento de $8 ; 16$ e 24 horas. Após as irrigações, verificou que a área molhada nos perfis verticais aumentou com a aplicação de maiores volumes de água; as dimensões atingidas foram de 52 a $113 \mathrm{~cm}$ de profundidade e de 50 a $110 \mathrm{~cm}$ de afastamento lateral, em relação ao ponto de gotejamento. Para $3 \mathrm{~L} \mathrm{~h}^{-1}$, após cinco aplicações com intervalos semanais, totalizando 70,5 L, verificou que a umidade máxima atingida no bulbo molhado foi $30 \%$, quando a umidade média do solo, de 0 a $100 \mathrm{~cm}$ de profundidade, era 22\%; a máxima expansão lateral da água no bulbo foi de $70 \mathrm{~cm}$, e a profundidade máxima foi de 90 a $100 \mathrm{~cm}$; os valores máximos de umidade concentraram-se na região central do bulbo, concordando com BOTREL (1988), que utilizou um Latossolo Vermelho-Amarelo, gotejador de $10 \mathrm{~L} \mathrm{~h}^{-1}$, aplicando $30 \mathrm{~L}$ de água, obteve bulbo com 60 a $70 \mathrm{~cm}$ de profundidade e $65 \mathrm{~cm}$ de raio de expansão lateral. O máximo teor de água situou-se no centro do bulbo, na faixa de 30 a $40 \mathrm{~cm}$ de profundidade. $O$ raio de expansão lateral da umidade na superfície do solo esteve ao redor de $50 \mathrm{~cm}$.

A quantidade de nutrientes aplicados é importante, e a fertirrigação tem sido mais eficiente que a adubação convencional (MIRANDA et al., 2006). Em experimento realizado por esses autores, a maior disponibilidade de fósforo no solo aumentou a produtividade de melão com fertirrigação, enquanto os maiores valores de $\mathrm{pH}$ do solo melhoraram a qualidade dos frutos.

Diversos fertilizantes podem ser utilizados para a fertirrigação, mas os adubos fosfatados (superfostato simples, superfosfato triplo e o monofosfato de amônio) podem causar obstruções de emissores e incrustações nas canalizações, principalmente quando a água é alcalina. A solução desse problema poderá estar na utilização do ácido fosfórico como fonte de fósforo, que também é vantajoso economicamente, pois, em irrigação localizada, geralmente é utilizado o monofosfato de amônio purificado, que possui maior preço. Entretanto, utilizando-se desse ácido, faz-se necessário o estudo da distribuição do fósforo no perfil do solo, a influência sobre o pH do mesmo e o comportamento dos microrganismos que nele habitam (BARRETO, 2004).

Este trabalho teve o objetivo de avaliar a influência da frequiência das irrigações e das fertirrigações utilizando ácido fosfórico como fonte de fósforo, sobre o $\mathrm{pH}$ e o teor de fósforo no solo.

\section{MATERIAL E MÉTODOS}

O experimento foi conduzido na UNESP - Câmpus de Jaboticabal - SP, nas coordenadas geográficas $21^{\circ} 15^{\prime}$ sul, $48^{\circ} 18^{\prime}$ oeste e altitude de $575 \mathrm{~m}$, em solo com declividade média de $8 \%$. De acordo com a classificação de solos da EMBRAPA (1999), o solo da área corresponde ao Latossolo Vermelho eutroférrico típico, textura muito argilosa, A moderado. As características químicas do solo foram determinadas antes da implantação do experimento (Tabela 1), e os valores de análise física e de retenção de água no solo encontram-se na Tabela 2.

O experimento iniciou-se no dia 27 de agosto de 2003 e constou de oito tratamentos e quatro repetições, com 32 parcelas, correspondendo a 32 pontos de gotejamento no solo, com delineamento experimental em blocos ao acaso. Os tratamentos corresponderam às combinações de quatro freqüências de irrigação ( $1 ; 3 ; 5$ e 7 dias) e duas doses de fósforo ( 0 e $50 \mathrm{~kg} \mathrm{ha}^{-1}$ de $\left.\mathrm{P}_{2} \mathrm{O}_{5}\right)$, distribuídos conforme esquema da Figura 1. 
TABELA 1. Resultados da análise química do solo da área experimental.

\begin{tabular}{|c|c|c|c|c|c|c|c|c|c|c|}
\hline \multirow{2}{*}{$\begin{array}{l}\text { Profundidade } \\
\qquad(\mathrm{cm})\end{array}$} & \multirow{2}{*}{$\begin{array}{c}\mathrm{pH} \\
\mathrm{em} \mathrm{CaCl}_{2}\end{array}$} & \multirow{2}{*}{$\begin{array}{l}\text { M.O. } \\
\left(\mathrm{g} \mathrm{dm}^{-3}\right)\end{array}$} & \multirow{2}{*}{$\begin{array}{l}\text { P resina } \\
\left(\mathrm{mg} \mathrm{dm}^{-3}\right)\end{array}$} & K & $\mathrm{Ca}$ & $\mathrm{Mg}$ & $\mathrm{H}+\mathrm{Al}$ & SB & $\mathrm{T}$ & \multirow{2}{*}{$\begin{array}{c}\mathrm{V} \\
(\%)\end{array}$} \\
\hline & & & & \multicolumn{6}{|c|}{$\mathrm{mmol}_{\mathrm{c}} \mathrm{dm}^{-3}$} & \\
\hline $0-20$ & 4,9 & 25 & 19 & 2,6 & 22 & 12 & 38 & 36,6 & 74,6 & 49 \\
\hline $20-40$ & 5,0 & 20 & 7 & 0,8 & 20 & 11 & 38 & 31,8 & 69,8 & 46 \\
\hline $40-60$ & 4,9 & 16 & 3 & 0,4 & 19 & 10 & 34 & 29,4 & 63,4 & 46 \\
\hline $60-80$ & 5,3 & 14 & 3 & 0,2 & 18 & 10 & 22 & 28,2 & 50,2 & 56 \\
\hline $80-100$ & 5,2 & 11 & 3 & 0,1 & 17 & 06 & 20 & 23,1 & 43,1 & 54 \\
\hline
\end{tabular}

TABELA 2. Valores de análise física e de retenção de água do solo da área experimental.

\begin{tabular}{|c|c|c|c|c|c|c|c|c|}
\hline \multirow{2}{*}{$\begin{array}{l}\text { Profundidade } \\
(\mathrm{cm})\end{array}$} & \multirow{2}{*}{$\begin{array}{c}\text { Argila } \\
\%\end{array}$} & \multirow{2}{*}{$\begin{array}{l}\text { Silte } \\
\%\end{array}$} & \multirow{2}{*}{$\begin{array}{c}\text { Areia } \\
\%\end{array}$} & \multicolumn{2}{|c|}{ Massa Específica $\left(\mathrm{g} \mathrm{cm}^{-3}\right)$} & \multicolumn{3}{|c|}{ Umidade Volumétrica $\left(\mathrm{m}^{3} \mathrm{~m}^{-3}\right)$} \\
\hline & & & & solo & partículas & $\theta \mathrm{s}$ & $\theta \mathrm{cc}$ & $\theta p m p$ \\
\hline $0-20$ & 66 & 15 & 19 & 1,40 & 2,8 & 0,472 & 0,399 & 0,266 \\
\hline $20-30$ & 58 & 22 & 19 & 1,42 & 2,8 & 0,442 & 0,404 & 0,293 \\
\hline $30-40$ & 63 & 19 & 18 & 1,37 & 2,7 & 0,478 & 0,399 & 0,280 \\
\hline
\end{tabular}

Fonte: LOPES (2003)

Para o estabelecimento das doses, tomou-se como base a recomendação de adubação para a cultura da laranja no Estado de São Paulo (RAIJ et al., 1997) e os resultados da análise do solo. Supondo-se um pomar com produção de $31 \mathrm{a} 40 \mathrm{t} \mathrm{ha}^{-1}$ e teor de fósforo no solo de 13 a $30 \mathrm{mg} \mathrm{dm}^{-3}$, utilizam-se $50 \mathrm{~kg} \mathrm{ha}^{-1}$ de $\mathrm{P}_{2} \mathrm{O}_{5}$, o que representa aproximadamente $160 \mathrm{~g}_{\text {planta }}{ }^{-1}$, para um pomar de espaçamento 7,0 x 4,5 m (317 plantas $\left.\mathrm{ha}^{-1}\right)$. As aplicações foram realizadas durante um mês, e as doses foram divididas em cinco aplicações semanais, com $10 \mathrm{~kg} \mathrm{ha}^{-1}$ de $\mathrm{P}_{2} \mathrm{O}_{5}$. Em cada aplicação, as parcelas dos tratamentos 1 a 4 receberam $20 \mathrm{~L}$ de água, e as parcelas dos tratamentos 5 a 8 receberam $20 \mathrm{~L}$ da mistura de água e ácido fosfórico, totalizando $100 \mathrm{~L}$ após as cinco aplicações, procurando-se obter bulbo molhado com profundidade de aproximadamente $80 \mathrm{~cm}$, baseado em ZANINI (1991).

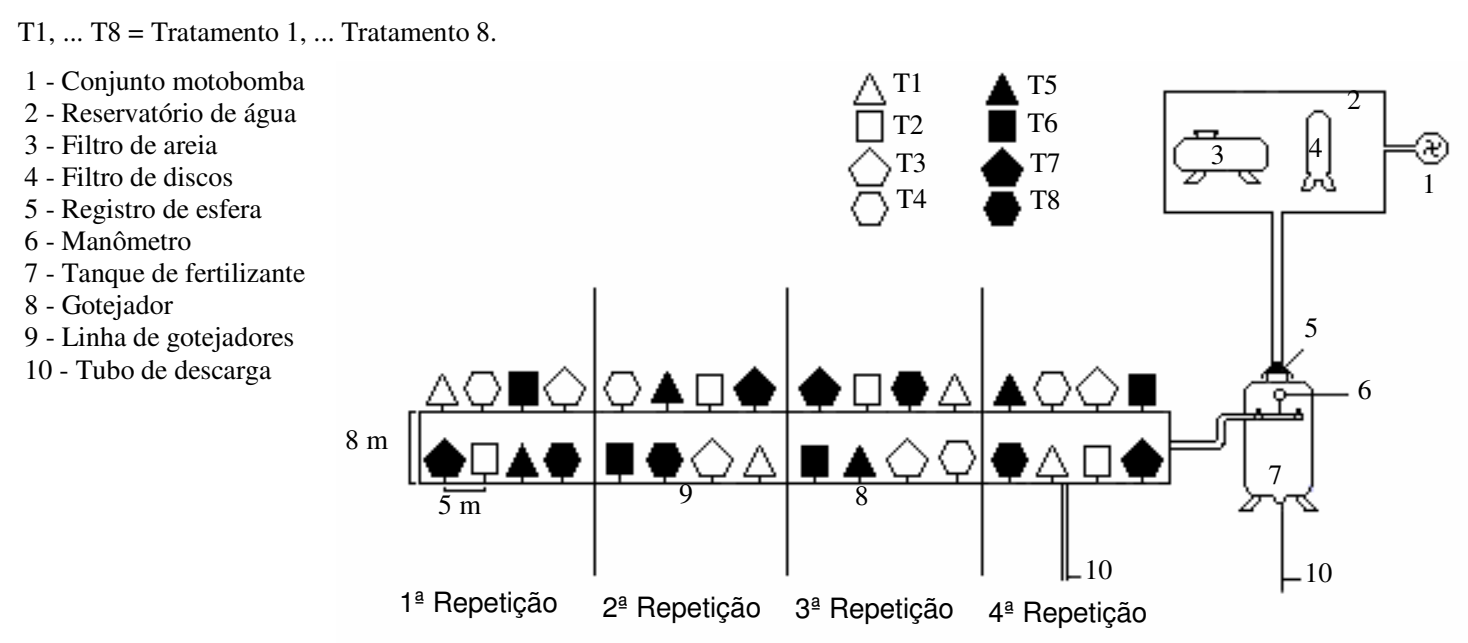

FIGURA 1. Esquema da distribuição dos tratamentos no campo com o sistema de fertirrigação.

Os cálculos dos tempos para a realização das fertirrigações foram realizados com a equação que descreve a concentração de uma solução em tanque de derivação de fluxo, quando é estabelecida uma relação entre o volume que deve passar pelo tanque e seu próprio volume (FAO, 1986): $\mathrm{C}_{\mathrm{t}}=\mathrm{C}_{0} \mathrm{e}^{-(\mathrm{V} / \mathrm{v})}$, em que, $\mathrm{C}_{\mathrm{t}}$ - concentração da solução no tanque após o tempo $\mathrm{t}, \mathrm{mg} \mathrm{L}^{-1} ; \mathrm{C}_{0}$ concentração inicial da solução colocada no tanque, $\mathrm{mg} \mathrm{L}^{-1}$; e - base do logaritmo neperiano; V volume que passou pelo tanque, $\mathrm{L}, \mathrm{e} \mathrm{v}$ - volume do tanque, $\mathrm{L}$. 
O tempo para a aplicação do ácido aos tratamentos foi de $5 \mathrm{~h}$ 20min; após esse período, os microtubos foram estrangulados com um anel de $20 \mathrm{~mm}$ de diâmetro (Figura 2), para interrupção do gotejamento. Após a aplicação de ácido aos tratamentos 5; 6; 7 e 8, os tubos de descarga do tanque e da linha de gotejamento eram abertos para a lavagem do tanque e da linha de gotejo. Em seguida, iniciava-se a aplicação dos tratamentos 1; $2 ; 3$ e 4, que recebiam apenas 20 L de água.

Vinte e quatro horas após o término da última aplicação em cada tratamento, nos bulbos molhados, foram abertas trincheiras na transversal à linha de gotejadores e, com uma espátula, foi preparado um plano vertical, possibilitando a visualização e a demarcação do contorno do bulbo.

No plano vertical formado, foram demarcadas quadrículas de $100 \mathrm{~cm}^{2}$, abrangendo todo o bulbo (Figura 3). Para cada quadrícula, coletaram-se amostras de solo de aproximadamente, 0,5 kg, para a determinação de umidade, $\mathrm{pH}$ e teor de fósforo. Distante de $2 \mathrm{~m}$ da periferia do bulbo molhado, no mesmo plano vertical das trincheiras, foram retiradas amostras de uma coluna de quadrículas (coluna de referência), para realização das mesmas análises das amostras do interior do bulbo.

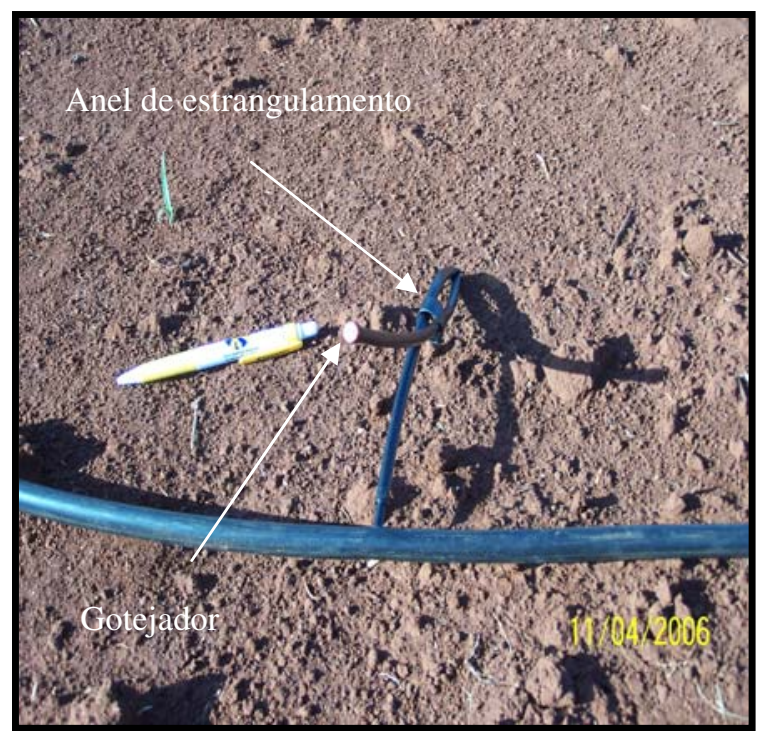

FIGURA 2. Interrupção do gotejamento com o dobramento do microtubo e do gotejador utilizado.

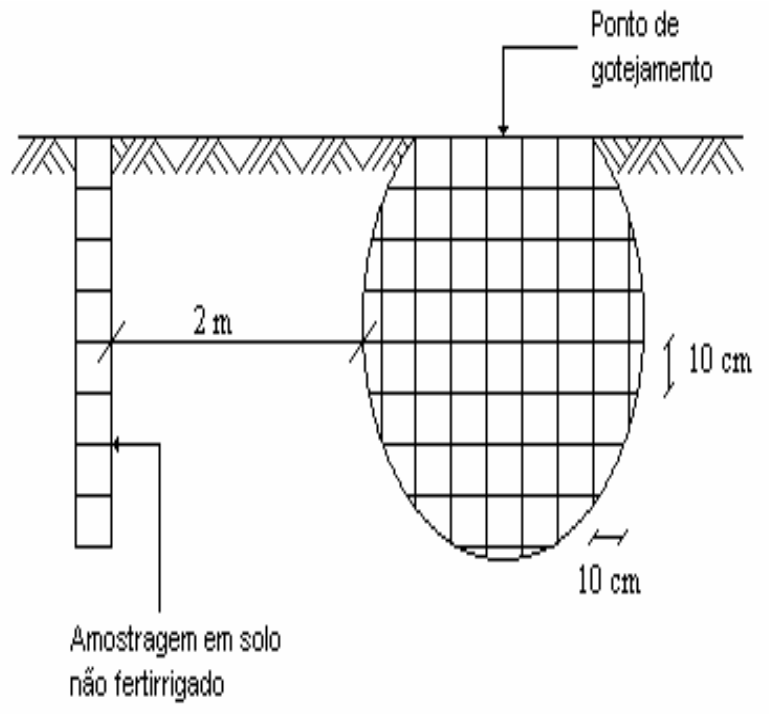

FIGURA 3. Esquema de demarcação das quadrículas para amostragem de solo. Fonte: ZANINI, 1991.

As análises de umidade foram realizadas pela diferença de massas obtidas com a pesagem das amostras antes e após a utilização de estufa a $105^{\circ} \mathrm{C}$, durante 24 horas.

Para a determinação do teor de fósforo e do $\mathrm{pH}$ do solo, as amostras foram destorroadas, secas à sombra, peneiradas (peneira de $2 \mathrm{~mm}$ ) e enviadas ao laboratório. O teor de fósforo foi determinado, utilizando-se do método da resina, e a leitura do $\mathrm{pH}$ foi realizada em peagâmetro ( $\mathrm{pH}$ em cloreto de cálcio).

\section{RESULTADOS E DISCUSSÃO}

Nas Figuras 4 e 5, pode-se verificar que a freqüência de aplicação não influenciou na distribuição da umidade, pois os tratamentos apresentaram distribuições laterais semelhantes e também foram semelhantes entre si as médias desses tratamentos; a máxima variação de umidade $(2,18 \%)$ ocorreu entre as médias dos tratamentos 6 e 4 (23,84\% e 21,66\%, respectivamente). Também, quanto mais distante lateralmente do ponto-fonte, menor foi a umidade do solo, concordando com ZANINI (1991) e BARRETO (2004). 


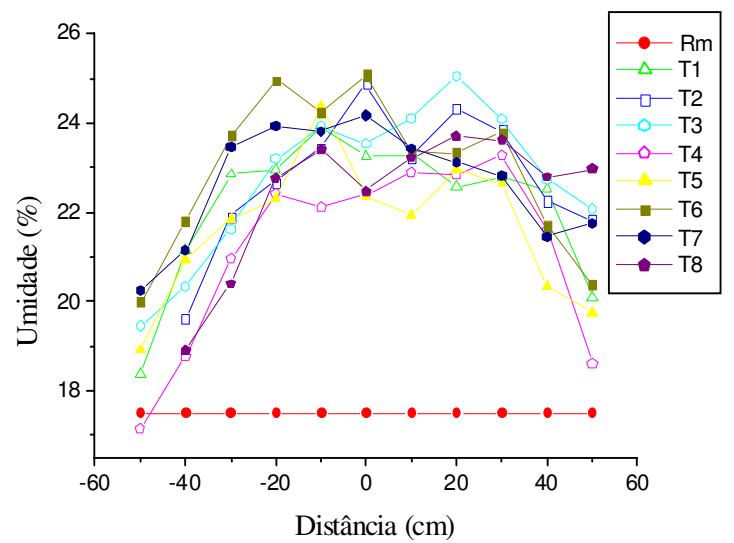

FIGURA 4. Distribuição lateral da umidade nos bulbos molhados dos tratamentos, e umidade média das colunas de referência.

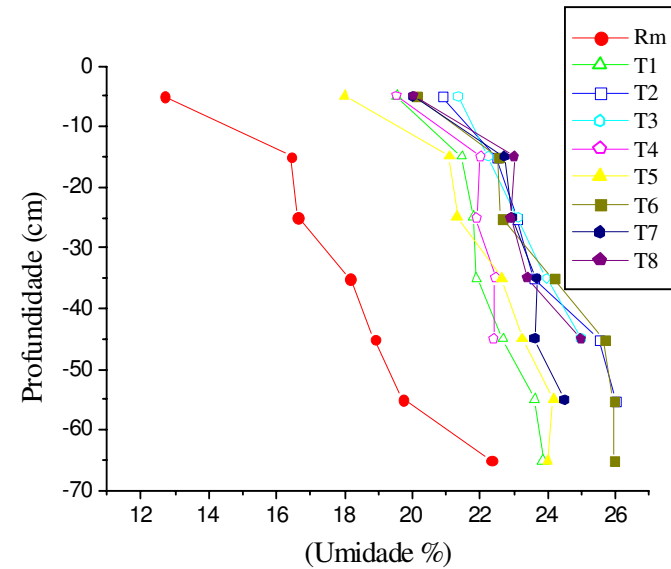

FIGURA 5. Distribuição da umidade em profundidade nos bulbos molhados dos tratamentos, e da umidade média das colunas de referência.

Na Figura 5, pode-se observar que ocorreu aumento da umidade do solo em relação ao solo não-irrigado (Rm); mesmo nas camadas mais profundas $(60$ a $70 \mathrm{~cm})$, a umidade nessa região do bulbo foi maior que a umidade original do solo (referência). Esses resultados coincidem com os obtidos por ZANINI (1991), que obteve aumento da umidade até $70 \mathrm{~cm}$ de profundidade. No entanto, observa-se que as freqüências de aplicações adotadas nos tratamentos resultaram em semelhantes distribuições de umidade em relação à profundidade no bulbo molhado. Isso ocorreu porque o volume total de água ou de água mais ácido até a última aplicação foi o mesmo para todos os tratamentos (100 litros).

\section{pH do solo}

Os resultados da Figura 6 indicam que, sem a adição de ácido fosfórico, os valores de $\mathrm{pH}$ do solo foram semelhantes para as diferentes frequiências de aplicação. Assim, os valores médios de pH para esses tratamentos assemelham-se aos valores obtidos para as colunas de referência (Rm). Entretanto, em torno do ponto de gotejamento $(10 \mathrm{~cm}$ de profundidade e $10 \mathrm{~cm}$ de expansão lateral), nota-se pequena elevação do $\mathrm{pH}$; isso provavelmente ocorreu devido ao efeito do $\mathrm{pH}$ da água utilizada na irrigação, que era aproximadamente igual a 7.

Pela Figura 7, observa-se a diminuição do $\mathrm{pH}$ nas camadas até $40 \mathrm{~cm}$ de profundidade, apresentando média geral de 4,5, inferior à média do solo que não recebeu fertirrigação, que foi de

4,8. A redução do pH nessas camadas ocorreu pela adição de ácido fosfórico no sistema de irrigação. Porém, à medida que se aumenta a profundidade do solo e a distância lateral em relação ao ponto de gotejamento, esses valores tendem a aumentar. Também pela Figura 7, observa-se que as maiores reduções do $\mathrm{pH}$ do solo ocorreram até a faixa de 10 a $20 \mathrm{~cm}$ de profundidade e de 10 a $20 \mathrm{~cm}$ ao redor do gotejador, concordando com BARRETO (2004). Observa-se também, que os valores do $\mathrm{pH}$ nos bulbos para os tratamentos 6; 7 e 8 (Figuras 7B; 7C e 7D, respectivamente) foram semelhantes aos do tratamento 5 (Figura 7A), indicando maior acidificação em torno dos $20 \mathrm{~cm}$ de expansão lateral e até $20 \mathrm{~cm}$ de profundidade do solo, demonstrando que as frequiências de fertirrigação (1; 3; 5 e 7 dias) provocaram efeitos semelhantes no $\mathrm{pH}$ dos bulbos das fertirrigações.

Os tratamentos que continham ácido fosfórico (5 a 8), representados pela Figura 7, apresentaram queda nos valores de $\mathrm{pH}$ do solo em comparação aos tratamentos 1 a 4 e ao solo nãoirrigado (referência).

Conforme RAIJ (1991), as maiores quantidades de fósforo disponíveis no solo encontram-se na matéria orgânica do solo ou com valores baixos de $\mathrm{pH}$ da solução do solo, porém na faixa de valores de 6,2 a 6,8 ocorre o pleno desenvolvimento da maioria das culturas (BARRETO, 2004). Já LOPES (1998) enfatiza que a correção do pH do solo influencia muito pouco a adsorção de fósforo pelo solo, e há necessidade de aplicação de altas doses de fósforo nos solos tropicais para alcançar altos índices de produtividade. 


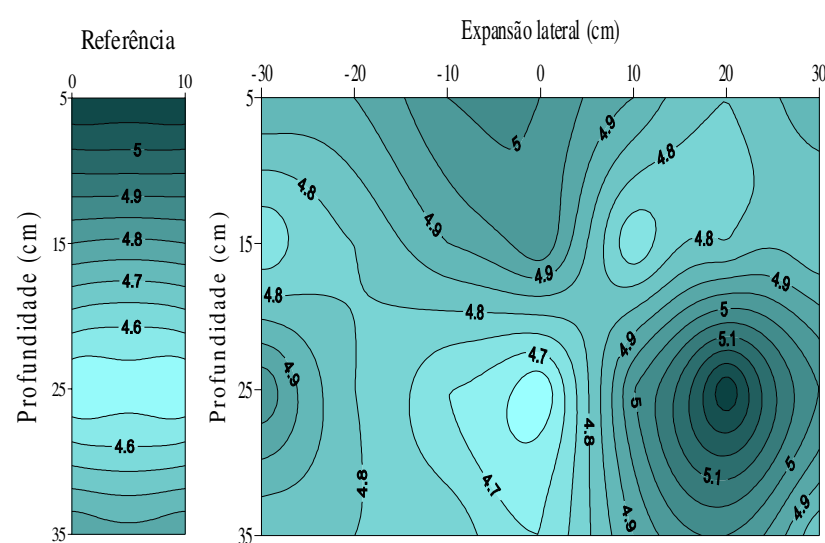

A
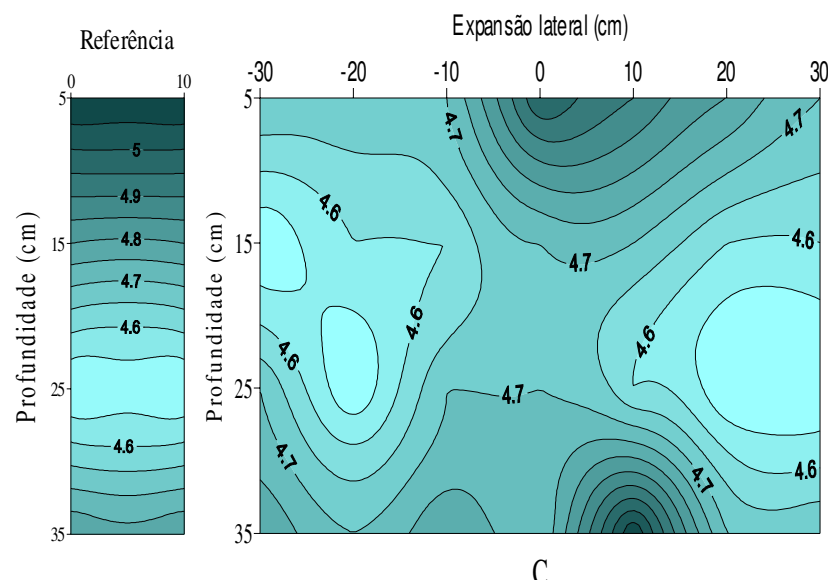

Referência
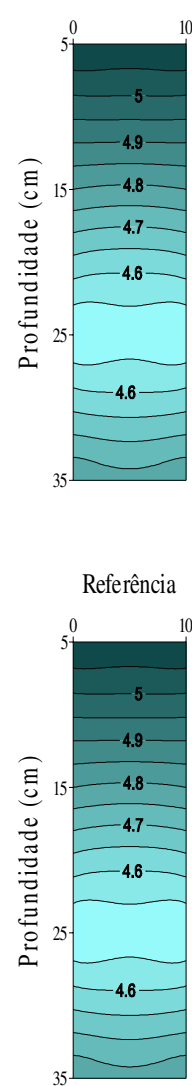

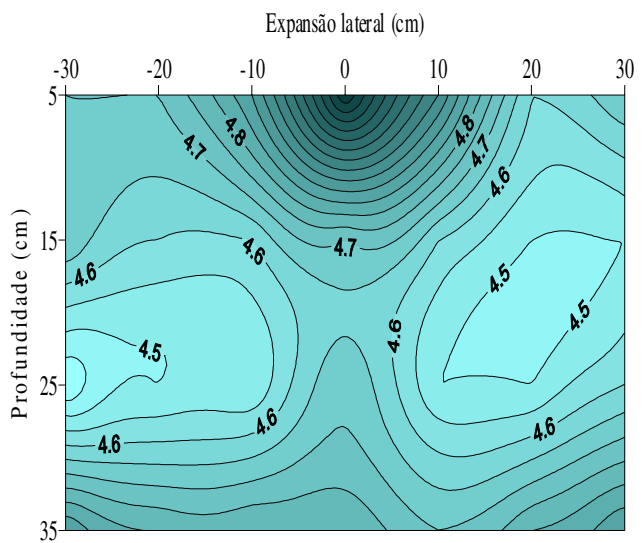

B

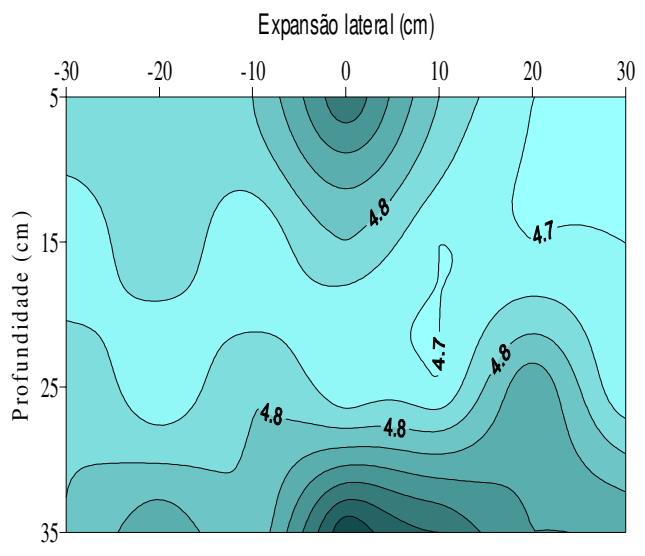

$\mathrm{D}$

FIGURA 6. Mapa de valores do pH do solo sem adição de ácido fosfórico e com as frequiências de aplicação: A) 1 dia; B) 3 dias; C) 5 dias; D) 7 dias.
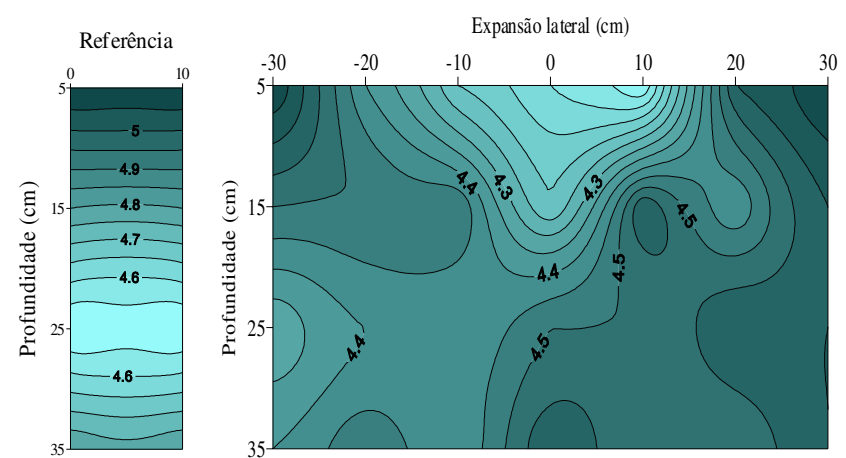

A

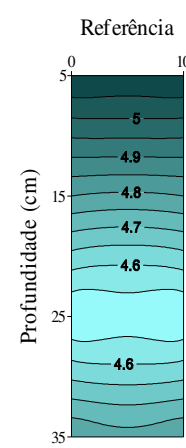

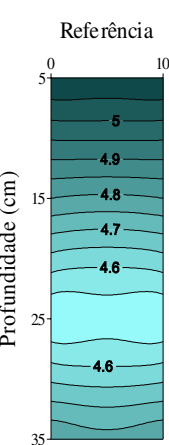

Referencia

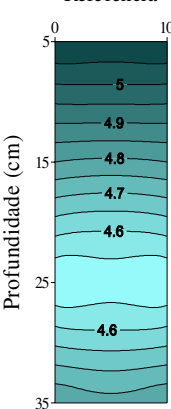

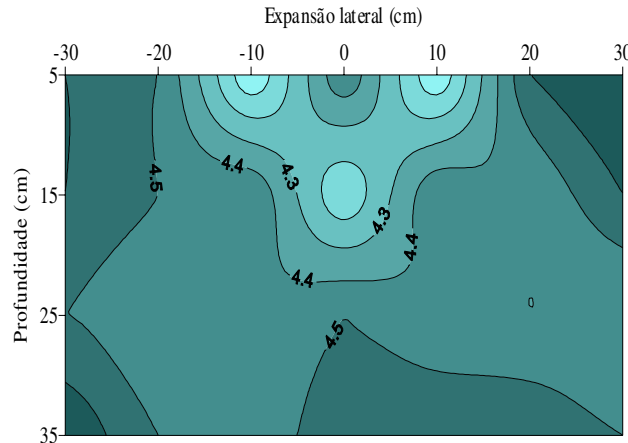

B

Expansão lateral (cm)

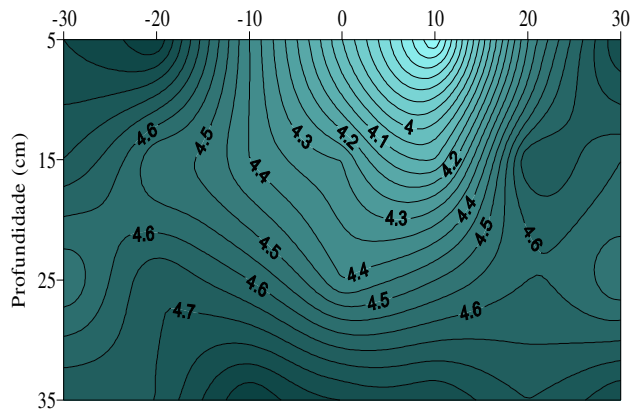

FIGURA 7. Mapa de valores do $\mathrm{pH}$ do solo com adição de ácido fosfórico $\left(50 \mathrm{~kg} \mathrm{ha}^{-1}\right.$ de $\left.\mathrm{P}_{2} \mathrm{O}_{5}\right)$ e com as freqüências de aplicação: A) 1 dia; B) 3 dias; C) 5 dias; D) 7 dias. 


\section{Teor de fósforo no solo}

Pela Figura 8, observa-se que as distribuições do fósforo foram semelhantes, ou seja, as irrigações, nas diferentes freqüências, não alteraram a distribuição do fósforo contido no solo. Também foram semelhantes os teores de fósforo dos tratamentos 1 a 4 em relação aos dados apresentados na coluna de referência $(\mathrm{Rm})$.

Os tratamentos de 1 a 4 (Figura 8) não influenciaram nos teores de fósforo; tanto para a expansão lateral quanto para a profundidade, resultaram em valores semelhantes ao solo nãoirrigado (referência). Esses resultados são coerentes com os obtidos por BARRETO (2004), que também não observou variações dos teores de fósforo no bulbo molhado, para um tratamento que não recebeu ácido fosfórico.
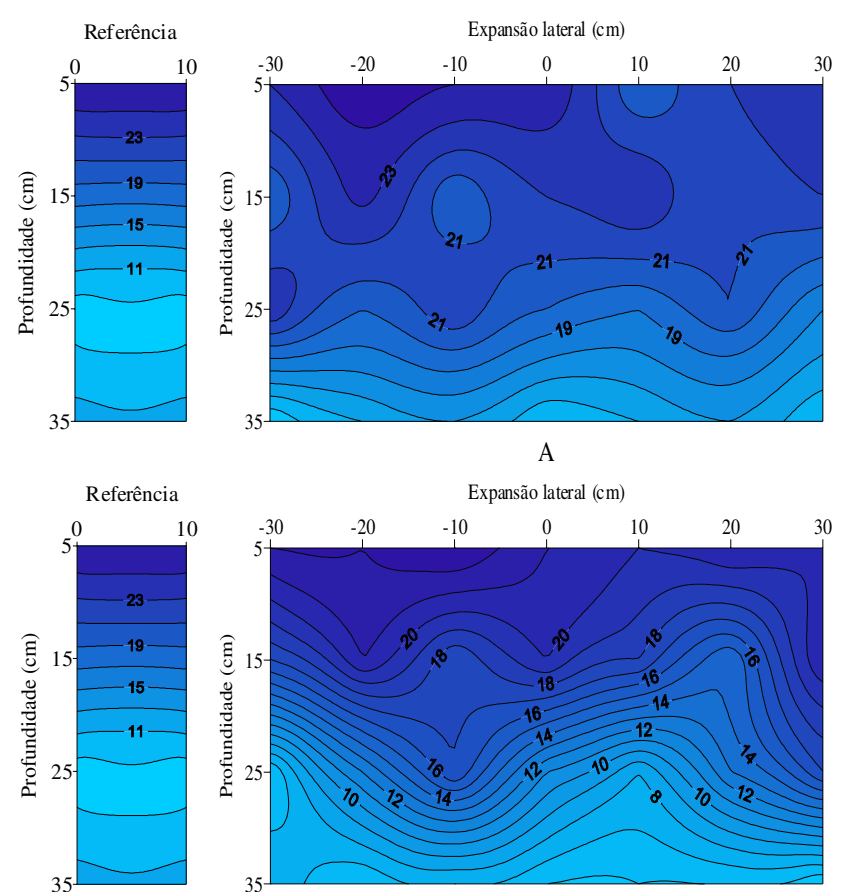

A

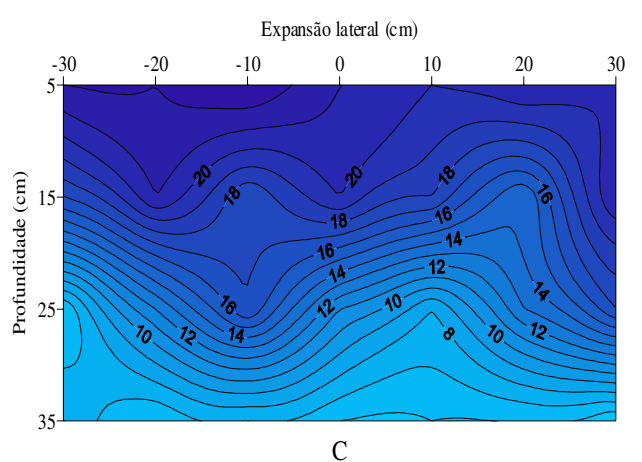

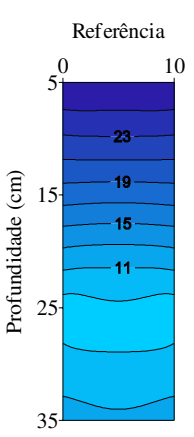

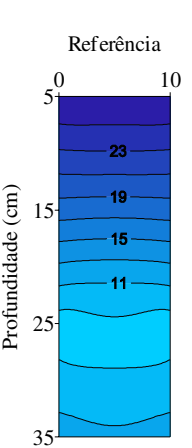

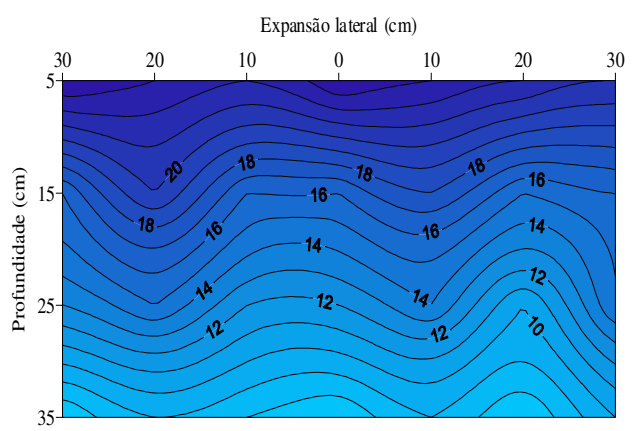

$\mathrm{B}$

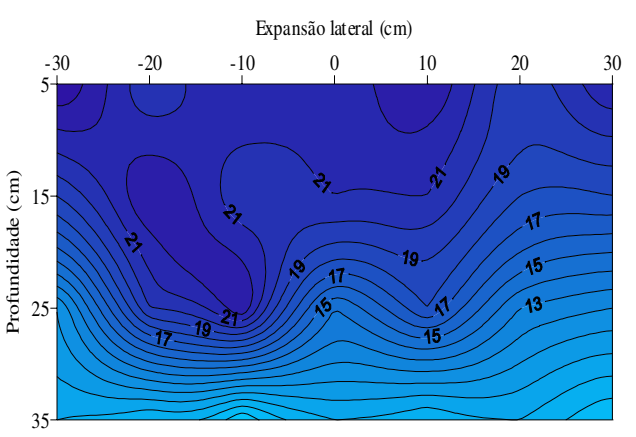

$\mathrm{D}$

FIGURA 8. Mapas do teor de fósforo do solo $\left(\mathrm{mg} \mathrm{dm}^{-3}\right)$ sem adição de ácido fosfórico, com as freqüências de aplicações: A) 1 dia; B) 3 dias; C) 5 dias; D) 7 dias.

A partir da Figura 9, pode-se observar que, com a aplicação de ácido fosfórico, os teores obtidos para o fósforo no solo e sua distribuição no bulbo molhado são semelhantes aos obtidos para o tratamento 5, caracterizando elevados teores ao redor do ponto de aplicação. Devido à baixa mobilidade desse nutriente no solo, a concentração foi maior até $30 \mathrm{~cm}$ de profundidade e atingiu expansão lateral entre 20 e $30 \mathrm{~cm}$ de raio, coincidindo, nessa região, com os menores valores de pH (Figura 7). Também comparando-se os tratamentos 5; 6; 7 e 8, verifica-se que as frequiências de aplicação não provocaram diferenças de distribuição do fósforo no bulbo molhado.

Os tratamentos 5 a 8, representados pela Figura 9, demonstraram o efeito da adição de ácido fosfórico no sistema de irrigação, provocando aumento da quantidade de fósforo no solo. Nessa Figura, é possível visualizar a nítida formação de isolinhas que atingem expansão lateral e profundidade próxima de $30 \mathrm{~cm}$, comprovando a baixa mobilidade do fósforo e a correlação com a acidificação do solo. Conforme apresentado na Tabela 2, sendo o solo do presente estudo muito argiloso, isso contribui para a pouca mobilização do fósforo no solo, em função da alta capacidade de adsorção do fósforo pelas partículas de argila. 

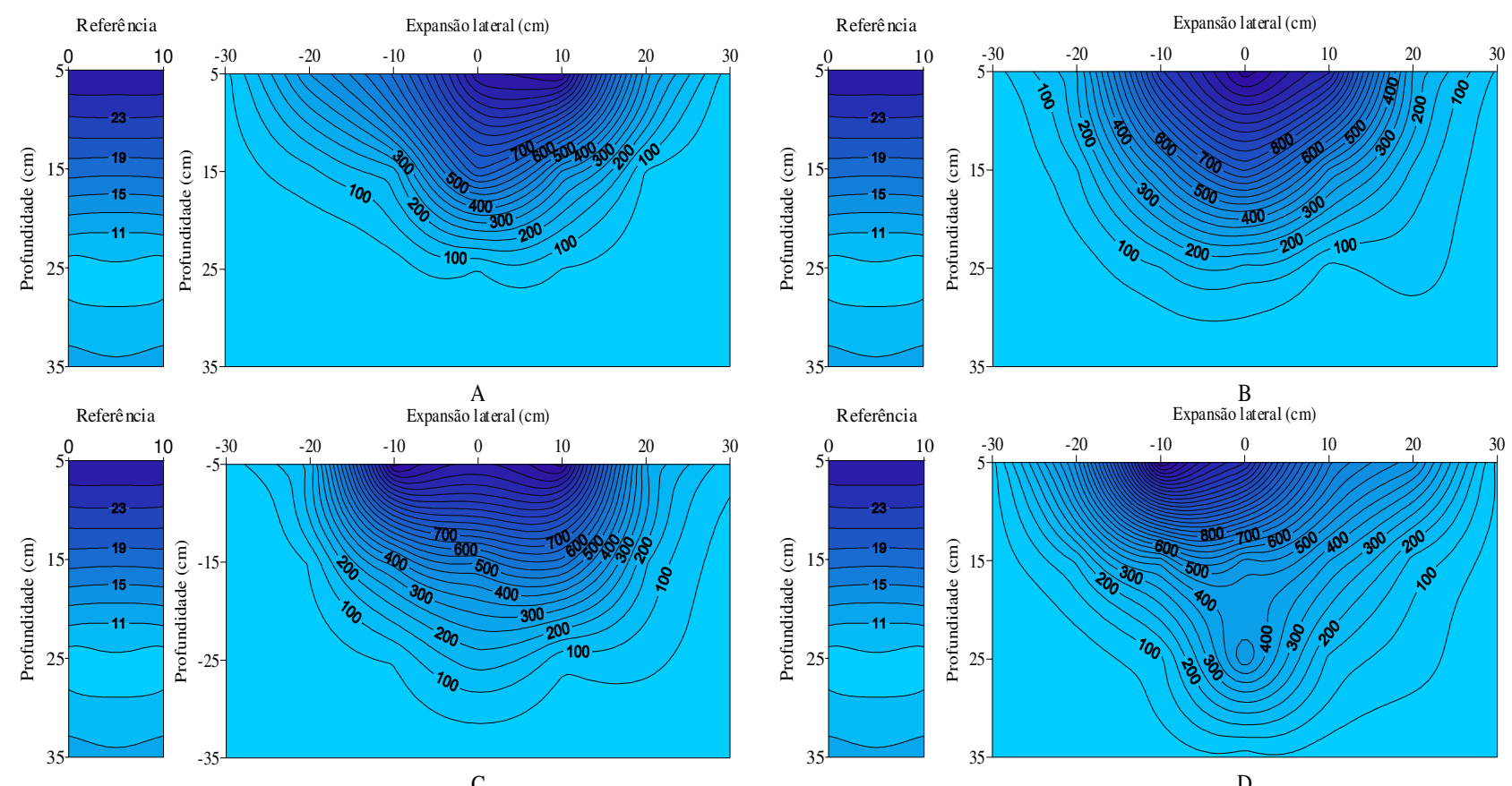

FIGURA 9. Mapas do teor de fósforo do solo $\left(\mathrm{mg} \mathrm{dm}^{-3}\right)$ para a aplicação de $50 \mathrm{~kg} \mathrm{ha}^{-1}$, com as freqüências de aplicações: A) 1 dia; B) 3 dias; C) 5 dias; D) 7 dias.

O ácido fosfórico pode ser uma solução para o entupimento de gotejadores, uma vez que, segundo REIS et al. (2005), os entupimentos causados por sólidos em suspensão ou por precipitações dos adubos fosfatados convencionais diminuem a eficiência do sistema de irrigação. Porém, VILLAS BÔAS et al. (1999) atentam para os danos que o ácido fosfórico poderá causar no sistema de irrigação, quando utilizado indiscriminadamente e sem manejo adequado, causando corrosão em peças metálicas. Conforme obtido no presente estudo, se utilizado adequadamente em fertirrigação, poderá atingir considerável profundidade no solo, pois, com outras formas de aplicação, as profundidades atingidas são limitadas. De acordo com VILLAS BÔAS et al. (2002), o efeito da saturação dos sítios de adsorção do solo provoca maior expansão lateral e em profundidade no solo.

Segundo BARRETO (2004), a amostra de 0 a $10 \mathrm{~cm}$ de profundidade e abaixo do ponto de


média de $1.242,5 \mathrm{mg} \mathrm{dm}^{-3}$ de $\mathrm{P}_{2} \mathrm{O}_{5}$, para amostras com essa mesma localização no bulbo, referente a $50 \mathrm{~kg} \mathrm{ha}{ }^{-1}$ de $\mathrm{P}_{2} \mathrm{O}_{5}$. Também BARRETO (2004) observou que o aumento da dose de $\mathrm{P}_{2} \mathrm{O}_{5}$ contribui para maior propagação do fósforo no bulbo molhado. Neste estudo, as médias gerais para a região analisada dos bulbos foram: 191; 218; 229 e $246 \mathrm{mg} \mathrm{dm}^{-3}$, para os intervalos de aplicações de 1; 3; 5 e 7 dias, respectivamente. Assim, aumentando-se os tempos de permanência do fósforo no solo, houve aumento da média geral, contrariando o esperado, que deveria ser a diminuição do teor de fósforo devido às reações de imobilização do mesmo.

\section{CONCLUSÕES}

As frequiências de 1; 3; 5 e 7 dias empregadas para a realização das irrigações e das fertirrigações não resultaram em diferentes distribuições de umidade, de valores de $\mathrm{pH}$ e de teores de fósforo no bulbo molhado.

A aplicação de $50 \mathrm{~kg} \mathrm{ha}^{-1}$ de $\mathrm{P}_{2} \mathrm{O}_{5}$ na forma de ácido fosfórico reduziu o $\mathrm{pH}$ do solo até $30 \mathrm{~cm}$ de distância lateral e até aproximadamente $40 \mathrm{~cm}$ em profundidade no bulbo molhado, chegando a apresentar valores na faixa de 3,6 a 4,0, coincidindo com os teores de fósforo que atingiram 710 a $1.410 \mathrm{mg} \mathrm{dm}^{-3}$. 


\section{REFERÊNCIAS}

BARRETO, A.K.G. Distribuição de fósforo no bulbo de gotejamento, aplicado via fertirrigação com ácido fosfórico e sua influência na respiração do solo. 2004. 90 f. Dissertação (Mestrado) Faculdade de Ciências Agrárias e Veterinárias de Jaboticabal, Universidade Estadual Paulista, Jaboticabal, 2004.

BOTREL, T.A. Simulação da distribuição espacial da água em solo irrigado com gotejador. 1988. 61 f. Tese (Doutorado em Irrigação e Drenagem) - Escola Superior de Agricultura "Luiz de Queiroz”, Universidade São Paulo, Piracicaba, 1988.

CHARLESWORTH, P.B.; MUIRHEAD, W.A. Crop establishment subsurface drip-irrigation: a comparison of point and area source. Irrigation Science, Heidelbderg, v.22, n.3-4, p.171-6, 2003.

DALRI, A.B.; CRUZ, R.L. Efeito da freqüência de irrigação subsuperficial por gotejamento no desenvolvimento de cana-de-açúcar (Saccharum spp.). Irriga, Botucatu, v.7, n.1, p.29-34, 2002.

ELOI, W.M.; SOUZA, V.F. de; VIANA, T.V. de A.; ANDRADE JÚNIOR, A.S. de; HOLANDA, R.S.F. de; ALCANTARA, R.M.C.M. de. Distribuição espacial do sistema radicular da gravioleira em função de doses de nitrogênio e potássio aplicados via fertirrigação. Irriga, Botucatu, v.9, n.3, p.256-69, 2004.

EMBRAPA. EMPRESA BRASILEIRA DE PESQUISA AGROPECUÁRIA. Sistema brasileiro de classificação de solos. Rio de Janeiro: Ministério da Agricultura e do Abastecimento, 1999. 412 p.

FAO. Food Agricultural Organization of the United Nations. Riego localizado. Roma: 1986. 203 p. (Publicación, 36)

LOPES, A. S. Manual de fertilidade do solo. 2.ed. Piracicaba: POTAFOS, 1998. 177 p.

LOPES, A S. Manejo da irrigação (tensiometria e balanço hídrico-climatológico) para a cultura do feijoeiro, em plantio direto e convencional. 2003. 94 f. Dissertação (Mestrado em Produção Vegetal) - Faculdade de Ciências Agrárias e Veterinárias, Universidade Estadual Paulista, Jaboticabal, 2003.

MIRANDA, N.O.; OLIVEIRA, T.S.; MEDEIROS, J.F.; LEVIEN, S.L.A. Causas da variação em produtividade e qualidade do melão em um Latossolo Vermelho-Amarelo fertirrigado. Ciência Rural, Santa Maria, v.36, n.2, p.487-93, mar/abr. 2006.

NOGUEIRA, C.C.P.; COELHO, E.F.; LEÃO, M.C.S. Características e dimensões do volume de um solo molhado sob gotejamento superficial e subsuperficial. Revista Brasileira de Engenharia Agrícola e Ambiental, Campina Grande, v.4, n.3, p.315-20, 2000.

RAIJ, B.Van.; CANTARELLA, H.; QUAGGIO, J.A.; FURLANI, A.M.C. (Ed.). Recomendações de adubação e calagem para o Estado de São Paulo. 2.ed. Campinas: IAC, 1997. 285 p. (Boletim Técnico 100).

REIS, E.F.; BARROS, F.M.; CAMPANHARO, M.; PEZZOPANE, J.E.M. Avaliação do desempenho de sistema de irrigação por gotejamento. Engenharia na Agricultura, Viçosa, v.13, n.2, p.74-81, 2005.

VILLAS BÔAS, R.L.; BÜLL, L.T.; FERNÁNDEZ, D.M. Fertilizantes em fertirrigação. In: FOLEGATTI, M.V. (Coord.) Fertirrigação: cítrus, flores e hortaliças. Guaíba: Livraria Editora Agropecuária, 1999. p.293-319.

VILLAS BÔAS, R.L.; ZANINI, J.R.; DUENHAS, L.H. Uso e manejo de fertilizantes em fertirrigação. In: ZANINI, J.R.; VILLAS BÔAS, R.L.; FEITOSA FILHO, J.C. (Org.). Uso e manejo da fertirrigação e hidroponia. Jaboticabal: Funep, 2002. p.1-25.

ZANINI, J.R. Distribuição de água e do íon K no solo aplicados por fertirrigação II. Teores de K no bulbo molhado. Irrigação e Tecnologia Moderna, Brasília, v.46, n. 1, p.24-38, 1991. 